if we believe that humanity, by its own exertions, can attain a higher and nobler destiny than any it has yet known, then we shall not fail.

\section{Overhead Lines and Outdoor Equipment on A.C. Systems}

Is a paper read recently in London before the Institution of Electrical Engineers, R. C. Hatton and J. McCombe lay down the guiding principles that for the efficient operation, maintenance and testing of electrical equipment in complex A.c. systems, it is of fundamental importance to provide adequate transport and communication systems, a carefully selected and trained staff at strategic points, and centralized control of all operations, and to enforce the strict observance of a suitable code of safety regulations. The maintenance of the various components of overhead lines and outdoor sub-stations, which the authors' experience has shown to be necessary or desirable, is detailed, and suitable intervals for such maintenance work are indicated. An analysis of faults is made for both the overhead lines and transformers on the system, and the steps are described which have been taken, or which should be taken, for counteracting them. The predominance of faults due to lightning is emphasized and the precautions which can be taken are discussed. Finally, the authors indicate the developments they consider to be desirable to minimize maintenance costs and at the same time to improve the reliability of electricity distribution, with special reference to the system of the Yorkshire Electric Power Co.

\section{Institution of Electrical Engineers: Scholarships for 1945}

The Council of the Institution of Electrical Engineers will this year consider the award of three research scholarships and grants, and seven scholarships for undergraduates and students to attend universities and technical colleges. These awards will be made subject to the regulations laid down by the Ministry of Labour and National Service regarding the candidates' ages at the commencement of their courses. Research Scholarships : Ferranti Scholarship, $£ 250$ per annum for two years; Swan Memorial Scholarship, £120 for one year; War Thanksgiving Education and Research Fund, grants up to $£ 100$ for one year. Student Scholarships : Duddell Seholarship, £150 per annum for three years; William Beodie Esson Scholarship, $£ 120$ per annum for two years, renewable in approved cases for a third year ; Silvanus Thompson Scholarship, $£ 100$ per annum, plus tuition fees for two years; David Hughes Scholarship, $£ 100$ for one year; Salomons Scholarship, $£ 100$ for one year; Paul Scholarship, £50 per annum for two years; Thorrowgood Scholarship, $£ 25$ per annum for two years. Full particulars can be obtained from the Secretary, Institution of Electrical Engineers, Savoy Place, Victoria Embankment, London, W.C.2. The closing date for receiving applications is April 15, 1945, and the awards will be made towards the end of June.

\section{Conference on X-Ray Diffraction Analysis}

THE X-ray Analysis Group of the Institute of Physics will hold a conference during April 12 and 13, at the Royal Institution, London, under the chairmanship of Sir Lawrence Bragg. The programme includes a lecture by Prof. J. D. Bermal on "The Future of X-ray Analysis", and a series of papers on new and improved methods. Discussions are to be included on the equipment of a laboratory for X-ray analysis, the interpretation of $\mathrm{X}$-ray diffraction by optical principles, and the proposal to convert X-ray wave-lengths to absolute values. Further particulars may be obtained from the honorary secretary of the Group, Dr. H. Lipson, Crystallographic Laboratory, Free School Lane, Cambridge.

\section{Care of Laboratory Animals}

The Universities Federation for Animal Welfare (UFAW), 284 Regent's Park Road, Finchley, London, N.3, has been collecting information for a handbook on the care of laboratory animals. Major C. W. Hume and Dr. F. Jean Vinter state that they still require information about maintaining healthy stocks of the larger species - cats, dogs, the smaller ungulates and primates. These species will not be dealt with in detail in the handbook, but references will be given to published accounts of methods of maintaining healthy and contented stocks and a list provided of laboratories at which advice on the subject can be given at first-hand.

\section{Announcements}

THE Senatus of the University of Edinburgh has awarded Cameron Prizes for 1945 "for a highly important and valuable addition to Practical Therapeutics" to Sir Alexander Fleming in recognition of his discovery of penicillin, and to Sir Howard Florey in recognition of his work in making possible the clinical application of penicillin.

THE title of professor of chemical pathology in the University of London has been conferred on Dr. E. J. King, in respect of the post held by him at the British Postgraduate Medical School.

Prof. Douglas Hay, honorary professor of mining in the University of Sheffield, has been appointed a member of the Board for Mining Examinations in succession to the late Mr. Robert Clive.

The trustees of the Miners' Welfare National Scholarship Scheme, established by the Miners' Welfare Commission for the provision of university scholarships for workers in or about coal mines and their sons and daughters, have appointed Prof. J. F. Duff, vice-chancellor of the University of Durham, to be chairman of the Selection Committee in succession to Sir Franklin Sibly; and Prof. W. E. Curtis, professor of physics at King's College, Newcastle-upon-Tyne, to be a member of the Committee in succession to Prof. A. M. Tyndall.

The Royal Society of South Africa elected the following to fellowship during 1944 : Dr. R. A. Dyer, chief of the Division of Botany and Plant Pathology, Pretoria, well known for work on the Euphorbias; Dr. N. Sapeika, assistant professor of pharmacology, University of Cape Town, and author of "Actions and Uses of Drugs" ; and L. H. Wells, lecturer in anatomy, University of the Witwatersrand, and anthropologist.

Erratum. In Nature of February 24, p. 233, Prof. Sydney Chapman was wrongly described as "chief professor of mathematics, University of London". Prof. Chapman is chief professor of mathematics in the Imperial College of Science and Technology, University of London. 